\title{
Erratum to: Labour Market Adjustments to Financing Conditions under Sectoral Rigidities in the Euro Area
}

\author{
Arno Hantzsche ${ }^{1}$ - Simon Savsek ${ }^{2}$. \\ Sebastian Weber ${ }^{3}$
}

Published online: 16 July 2018

C) Springer Science+Business Media, LLC, part of Springer Nature 2018

\section{Erratum to: Open Econ Rev \\ https://doi.org/10.1007/s11079-018-9485-0}

This article was published with errors that were introduced during the publication process by the publisher who accepts full responsibility and apologizes for any inconvenience. The corrections to the article appear below.

- The references to Fig. 2 in the text refer to the omitted figure printed here depicting the quarterly change in government bond yield spreads.

- The references to Fig. 3 a-c in the text refer to the figure misnumbered as Fig. 2. The correct label is: "Institutional indicators. Note: Lines depict median across countries. Manufacturing solid blue (dark) line; construction dashed blue (dark) line; services solid orange (light) line; public sector dashed orange (light) line."

- The references to Fig. 4 a-c in the text refer to the figure misnumbered as Fig. 3. The correct label is: "Baseline results. Note: Dashed lines 90\% confidence interval calculated with Driscoll-Kraay standard errors."

- The references to Fig. 5 a-c in the text refer to the figure misnumbered as Fig. 4. The correct label is: "Tightening and easing shocks. Note: Tightening (positive) spread shock blue (dark) line; easing (negative) spread shock orange (light) line.

The online version of the original article can be found at https://doi.org/10.1007/s11079-018-9485-0

Sebastian Weber

sweber@imf.org

1 National Institute of Economic and Social Research, London, UK

2 European Investment Bank, Luxembourg, Luxembourg

3 International Monetary Fund, Washington, DC, USA 


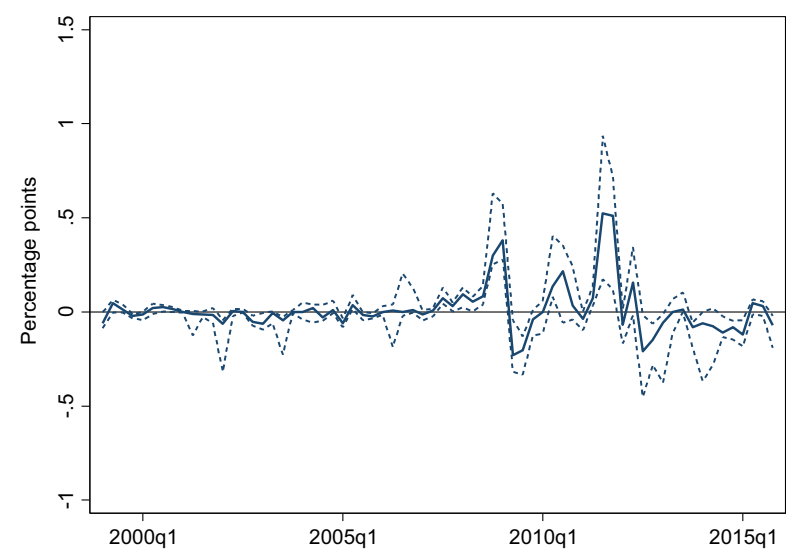

Fig. 2 Quarterly change in government bond yield spreads. Note: Quarterly change in percentage points, sample excluding programme period. Solid line depicts median across countries. Dashed lines depict interquartile range across countries

Dashed lines 90\% confidence interval calculated with Driscoll-Kraay standard errors."

- The references to Fig. 6 a-l in the text refer to the figure misnumbered as Fig. 5. The correct label is: "Responses by sector. Note: Dashed lines $90 \%$ confidence interval calculated with Driscoll-Kraay standard errors."

- The references to Fig. 7 a-c in the text refer to the figure misnumbered as Fig. 6. The correct label is: "Results for high and low EPL. Note: Low rigidity blue (dark) line (20th percentile of sample EPL); high rigidity orange (light) line (80th percentile of sample EPL). Dashed lines $90 \%$ confidence interval calculated with Driscoll-Kraay standard errors."

- The references to Fig. 8 a-c in the text refer to the figure misnumbered as Fig. 7. The correct label is: "Results for high and low union density. Note: Low rigidity blue (dark) line (20th percentile of sample union density); high rigidity orange (light) line (80th percentile of sample union density). Dashed lines $90 \%$ confidence interval calculated with Driscoll-Kraay standard errors."

- Figs. 1, 9 to 17, and corresponding references in the text are correct. 